\title{
The Role of the Environment and Colonization in Healthcare- Associated Infections
}

\author{
Julie D. Wohrley and Allison H. Bartlett
}

\section{Definition of Colonization}

Colonization is the survival of a microorganism on an internal (gastrointestinal, respiratory, or genitourinary tract) or external (skin) surface of the host without causing disease. Different types of organisms colonize different surfaces. For example, skin and the mucous membranes of the nose may be colonized with gram-positive organisms, including Staphylococcus aureus and coagulase-negative staphylococci [1]. The pharynx is colonized with gram-positive and gram-negative organisms including Streptococcus pneumoniae, Haemophilus influenzae, and Moraxella catarrhalis [2]. Gram-negative aerobic and anaerobic organisms commonly found colonizing the gastrointestinal tract include gram-negative aerobic and anaerobic bacteria and gram-positive organisms including Enterococcus and C. difficile.

Hosts encounter microbes on a nearly constant basis from the environment around them. A patient's own colonizing flora can result in hospital-associated infections when host defenses are compromised by underlying disease, immune compromise, or invasive devices. Alternatively, the healthcare environment can provide a source of pathogens, either by indirect transmission on the hands of healthcare workers (HCWs) or by direct transfer from environmental contamination.

The outcome of human-microbe interactions depends on the complex interplay of host defenses against microbial invasion and microbial virulence factors. If microbes are not killed by the immune system, a commensal relationship between the colonizer and the host may develop; alternatively, this may be the first step in the process of infection, damaging the host as a result of multiplication of the microorganism. Prolonged illness leading to immunodeficiency and breaks in barriers

\footnotetext{
J. D. Wohrley · A. H. Bartlett $(\bowtie)$

Department of Pediatrics, Section of Infectious Diseases, The University of Chicago

Medicine, Chicago, IL, USA

e-mail: abartlett@peds.bsd.uchicago.edu
} 
resulting from invasive devices or surgical procedures may be associated with a shift from colonization to infection.

A complex interaction occurs throughout the body between commensal organisms and the barriers they colonize, with research on the skin and gastrointestinal tract microbiome shedding light on these interactions. The skin is a protective barrier with large numbers of colonizing bacteria. The skin microbiome is inhabited by bacteria, fungi, viruses, archaea, and mites; however most research has focused on bacteria. The presence of various microbes may influence disease as evidenced by the shift from Staphylococcus epidermidis cultured from healthy skin in young children [3] to Propionibacterium acnes in teenagers with acne [4, 5]. Children with atopic dermatitis have a propensity to infection with Staphylococcus aureus [6]. Loss of skin integrity, as with wounds, burns, inflammation, or invasive devices, allows pathogens to enter.

The balance between host and flora is also important in the gut and is influenced by antibiotic usage, diarrheal diseases, and critical illness [7-9]. The gut provides both an essential immune response in maintaining health with normal flora stimulating proliferation of epithelial cells in small and large intestines, participating in development of competent gut-associated immune responses, as well as providing a physical barrier function against pathogen invasion through colonization resistance [10-12]. Inflammatory bowel disease is just one example of altered gut flora associated with a disease state.

The secretory antibody system is important in the defense against mucosal infections. Specific secretory immunoglobulin A (IgA), transported through secretory epithelia to the mucosal surface, inhibits pathogen colonization through microorganism entrapment in mucus and promotion of clearance of entrapped microbes via peristalsis or mucociliary movement [13]. IgA also plays a role in mucosal protection of the gut by binding to a mucous layer that separates commensal bacteria from the apical surface of intestinal epithelial cells [14].

\section{The Role of Host Flora in Hospital-Acquired Infections}

Patients admitted to the hospital bring with them their "normal" flora which may be very different in a previously healthy child than in a technology-dependent child who resides in a long-term care facility.

Colonization of children with organisms specific to their individual clinical conditions, such as Pseudomonas aeruginosa in a tracheostomy- and ventilator-dependent child, or multidrug-resistant Enterobacteriaceae in the GI tract of a neurologically impaired adolescent with neurogenic bladder and a history of frequent urinary tract infections, may lead to infection with these pathogens. These resident organisms may be transferred to the environment where they can be acquired directly by other patients or transmitted indirectly by HCW hands.

High-risk populations for acquisition of multidrug-resistant organisms include those who are critically ill, who are immunocompromised, or who have been hospitalized for long periods of time, either in acute care or long-term care settings. 
Additional risk factors include prolonged use of antibiotics and contact with colonized patients or the colonized/contaminated hands of HCW.

Colonizing organisms may produce invasive infection whether or not colonization is acquired in the hospital or the community. Colonization with methicillinresistant Staphylococcus aureus (MRSA) is a risk factor for subsequent invasive MRSA infection [15]. A study of relatedness between colonizing strains of $S$. aureus and those associated with invasive disease in adults found that more than $80 \%$ of $S$. aureus blood isolates were identical to those colonizing the patient's anterior nares [16]. Genotypes of S. aureus strains from surgical site infections were also noted to be identical to colonizing strains in more than $80 \%$ of surgical patients [17].

\section{The Role of Environmental Flora in Hospital-Acquired Infections}

The hospital environment represents a reservoir of organisms such as MRSA, vancomycin-resistant Enterococcus (VRE), and multidrug-resistant gram-negative pathogens as well as Clostridium difficile. Notably, these same drug-resistant organisms found on surfaces in acute care hospital settings can be found in outpatient settings [18-21].

Transmission between patients and the environment may occur directly from contaminated fomites, indirectly from fomites on HCW hands, or indirectly from patient to patient on HCW hands. $C$. difficile may be spread in this indirect fashion. For example, this organism may be first identified in the stool of hospitalized patients and then later found to be contaminating the hospital room and its contents, with spread to HCW hands and the hospital environment.

\section{Surface as a Reservoir}

Hospital surfaces may serve as both a reservoir and a vehicle of transmission for pathogens. Specific pathogens such as MRSA [22], Pseudomonas aeruginosa [23], Acinetobacter [24], and C. difficile can contaminate hospital surfaces because of their ability to survive in the environment. The amount of hospital surface contamination varies depending on body site of infection/colonization, patient type, and cleaning practices. VRE is commonly associated with environmental contamination, especially in the presence of diarrhea [25]. In a study of ICU patients, the rates of environmental contamination were higher for patients with more than one body site positive for VRE [26].

C. difficile is often identified from rooms of colonized and infected patients, proving difficult to eradicate due to resilience of the spores [27]. The frequency of positive environmental cultures for C. difficile is high; in one study $29 \%$ (11 of 38) of environmental cultures in rooms occupied by asymptomatic patients had positive cultures for $C$. difficile, and $49 \%$ (44 of 90) of cultures in rooms occupied by patients had $C$. difficile-associated diarrhea $(p=0.014)[25,28]$. Over $80 \%$ of the environmental isolates characterized in this study had an immunoblot type identical to that of the patient [28]. During an outbreak investigation in an adult long-term care facility, $C$. difficile skin isolates from asymptomatic patients and from environmental 
surfaces matched the source patient's isolate in 13/15 (87\%) and 11/19 (58\%) cases, respectively [29]. $C$. difficile has also been recovered from physician and nurse work areas $[27,30]$.

\section{Contact with Contaminated Surfaces or Equipment Contaminating Gloves or Hands of HCWs}

Given the potential for hospital surfaces to be contaminated with pathogens, it stands to reason that the hands, and even the gloves, of HCWs can become contaminated as well. Contamination of hands of HCWs occurs after direct patient care or contact with contaminated surfaces [31-33]. Positive environmental cultures were found to be a risk factor for development of hand/glove contamination [34]. Not surprisingly, the level of hand contamination has been shown to correlate with level of environmental contamination [35].

\section{Transmission of HAI from Roommates and Associated with Prior Room Occupants}

Prior room occupants infected with healthcare-associated (HCA) pathogens may provide a source of exposure to other patients [36, 37]. Admission to a room in which the prior occupant was infected or colonized with MRSA, VRE, Acinetobacter, or $C$. difficile is a risk factor for subsequent colonization or infection with these organisms [38-41].

Special terminal cleaning (after the patient has been discharged) of rooms previously occupied by patients with $C$. difficile infection, including the use of hydrogen peroxide vapor, has been implemented to reduce rates of subsequent infection [42]. These procedures have led to reduced rates of infection in patients subsequently admitted to a room where a prior room occupant was infected or colonized with $C$. difficile $[43,44]$.

\section{The Role of Identifying Colonization}

Since colonization may lead to infection, two basic strategies - horizontal and vertical - are employed to reduce HAIs. Horizontal strategies seek to broadly reduce the burden of common healthcare-associated pathogens including S. aureus, Enterococcus, gram-negative bacteria, and Candida through interventions such as hand hygiene and environmental cleaning. Vertical strategies target specific pathogens known to cause HAIs and utilize active surveillance testing as well as directed approaches to decrease colonization and prevent transmission and subsequent infection [45, 46].

General horizontal prevention strategies are approached elsewhere in this text and include hand hygiene, contact precautions, isolation, and PPE use (see Chap. 1, Principles of Infection Control).

Strategies applied to patients known or at risk for pathogen colonization when viewed from a vertical approach fall into three broad categories: active surveillance testing (AST), pathogen-specific isolation, and decolonization. 


\section{Active Surveillance Testing (Screening)}

Screening (active surveillance testing, or AST) involves detection of colonized patients using culture or molecular methods and typically focuses on high-risk pathogens, including S. aureus (MRSA), Enterococcus (VRE), and C. difficile, that are transmitted from person-to-person from colonized or infected patients [45, 47, 48]. Some of the principles, strategies, challenges, and controversies of AST will be discussed below.

\section{AST Samples}

Optimal samples for AST vary by pathogen. Specimens for MRSA testing are most frequently obtained from nares; however $S$. aureus also colonizes the skin, perineum, pharynx [49-52], GI tract [49], vagina [53], and axillae [49, 50], and additional sites of screening may be indicated depending on the clinical scenario and potential consequences of infection. Specimens may undergo culture-based or molecular methods for detection of $S$. aureus/MRSA.

VRE colonization is based on samples from stool, rectal, and perirectal swabs, using both molecular methods and culture-based methods [54]. Rectal or stool samples are also used for detection of multidrug-resistant gram-negative organisms such as extended-spectrum $\beta$-lactamase-producing Enterobacteriaceae, as well as carbapenemase-producing Enterobacteriaceae. Pseudomonas and Acinetobacter may be detected in multiple sites, depending on clinical situation, including the rectum, skin, nares, pharynx, wounds, urine, and trachea if the patient is mechanically ventilated.

\section{AST and Isolation (Screening and Isolation)}

The use of AST without additional interventions to reduce risk for transmission has not proven effective. Universal screening effort for pathogens has been most widely studied for MRSA and is considered to be controversial due to questions regarding its effectiveness in controlling spread, as well as cost [45]. Screening alone has not shown to be effective in reducing colonization and infection for MRSA $[55,56]$. Studies have failed to show benefit for a combination of AST and isolation in reducing VRE infection or colonization; however, outbreaks of VRE have been successfully controlled in hospital settings with use of active surveillance, contact precautions, patient isolation, and cohorting [57]. Similarly, active surveillance is most useful following outbreaks of MRSA [58].

A cluster randomized trial in intensive care units found that universal gown and glove use did not reduce overall acquisition of multidrug-resistant organisms (MDRO); there was, however, a small reduction in MRSA transmission noted as a secondary outcome [59]. Another prospective study of ICU patients failed to show a difference in MRSA transmission [60], with additional concerns for the psychosocial 
effect that isolation places on patients [61]. In observational studies, single room isolation was shown to reduce MRSA acquisition and infection among hospitalized patients [62, 63]. Current recommendations for MRSA colonized and infected patients include isolation in single rooms or cohorting [64, 65]. However, experts have called for a review of the current recommendations for contact precautions and isolation for MRSA colonization in view of the above stated concerns [66].

\section{AST, Isolation, and Targeted Decolonization Using Mupirocin}

The addition of targeted decolonization strategies to AST and isolation for control of spread of healthcare-associated pathogens has been most extensively studied to prevent MRSA spread in the hospital setting. Patients who are nasally colonized with $S$. aureus are more than twice as likely as non-colonized patients to develop $S$. aureus infection [1, 67, 68]. Carriage may be classified as persistent, intermittent, or noncarriage [69]. Persistent colonization is associated with an increased risk of infection compared with intermittent or non-carriers [70]. Carriers with high bacterial loads have a higher risk of infection and may be more likely to transmit the bacteria to their environment [70, 71]. Greater quantities of $S$. aureus are found in the nares of persistent $S$. aureus carriers compared with intermittent carriers [72, 73].

Much research exists regarding the efficacy of active surveillance cultures combined with decolonization to decrease $S$. aureus transmission and infection in adults, with growing literature in neonatal ICUs [74-76]. Intranasal antibiotics (mupirocin), with or without antibacterial skin washes (chlorhexidine), have been used in order to decrease the bacterial burden and prevent transmission and infection. Shortterm nasal mupirocin has been demonstrated to be effective in eradicating MRSA nasal carriage, with up to $90 \%$ success after 1 week of treatment, and 30-60\% efficacy for longer duration of follow-up, depending on patient profile and body sites colonized [77, 78]. Nasal mupirocin use in high-risk settings has been demonstrated to be effective in eradicating $S$. aureus nasal colonization and reducing the number of infections in ICU, hemodialysis, surgical, and long-term care settings [79-82].

In a study of nearly two million adult admissions, a significant reduction in the rate of MRSA transmission and infection was noted after introduction of an infection control bundle, which included decolonization of MRSA carriers and isolation $[83,84]$ as well as a hand hygiene program [84]. However, a crossover study of universal screening on surgical wards combined with targeted decolonization and contact precautions was unable to demonstrate reduction in MRSA infections despite high compliance with screening [85].

Nasal mupirocin decolonization of NICU infants with MRSA colonization in two units with high prevalence $(>25 \%)$ of MRSA colonization decreased the rate of MRSA infections [86]. However, a retrospective study in the USA failed to demonstrate benefit when nasal mupirocin was used for 5 days in colonized neonates in a unit with a baseline prevalence of around $2 \%$ [87]. This study showed that some NICU infants develop infection prior to detection of colonization and infants who remain in the NICU can become recolonized over time [87]. Taken together, these 
data suggest that decolonization measures may be most beneficial when the baseline rate of colonization is high. Additional NICU studies have found a high correlation between colonizing strains and infecting strains and confirmed high rates (42\%) of infections occurring before colonization is detected suggesting universal, rather than targeted, decolonization should be used to control the spread of MRSA [74]. Current recommendations suggest that decolonization may be considered in highrisk neonates during an MRSA outbreak or in cases of endemic MRSA when other measures are failing [88]. A recent Society for Hospital Epidemiology Association (SHEA) survey regarding practices for MRSA identification and eradication in NICUs noted that most $(86 \%)$ performed surveillance screening (AST) for MRSA in neonates with variability in timing of samples, sites sampled, isolation protocols, and decolonization strategies employed [89].

Recommendations for MSSA are less clear. Invasive MSSA infections occur 2.5 times more frequently than invasive MRSA infections in neonates, leading to significant morbidity and mortality [90]. Targeted screening followed by MSSA decolonization in a single NICU reduced incidence rates of MSSA-positive clinical cultures and MSSA infections by more than 50\% [91].

Mupirocin resistance among $S$. aureus isolates has been demonstrated in multiple studies, especially associated with prolonged use. High-level resistance has been associated with decolonization failure, and low-level resistance may be associated with early recolonization [71, 72]. Therefore, the long-term use of mupirocin is questioned, and alternatives to mupirocin for decolonization in those with mupirocin-resistant strains of MRSA are needed. However, in a long-term study examining use of mupirocin prophylaxis in the NICU over a 7-year period, the rate of S. aureus (MSSA and MRSA) infections decreased from 1.88 to 0.33 per 1000 patient days without any mupirocin-resistant isolates identified [92]. This finding is consistent with previous reports of low prevalence of resistance among $S$. aureus isolates from mupirocin-treated neonates [93].

The use of decolonization may be most effective for patients at risk of infection for short periods of time such as surgical patients, whose risk of infection may be less once the surgical site is closed, as well as ICU patients, whose risk may lower once they are discharged from the ICU $[94,95]$. This is of import given that patients are recolonized within weeks or months following decolonization, and thus the effect is often shortlived $[95,96]$. Mupirocin decolonization has been used specifically to reduce the risk of surgical site infections (SSIs) associated with gram-positive organisms. In a metaanalysis of 17 RCTs or quasi-experimental studies including adult cardiac and orthopedic surgery patients, mupirocin decolonization was found to be significantly protective against gram-positive SSIs, specifically $S$. aureus SSIs [46, 81, 97].

Preoperative $S$. aureus decolonization is not routinely recommended for most pediatric patients undergoing surgery, however the impact of preoperative colonization on risk of SSI in children has been examined in many small studies. Risk of SSI was not elevated in $S$. aureus-colonized children undergoing cardiac surgery [98]. Studies in adult cardiac surgery patients, however, suggest a benefit to mupirocinbased decolonization in prevention of SSI [99]; this topic as it pertains to cardiac surgery is discussed further in Chap. 11. 


\section{Use of Universal Decolonization Strategies: Chlorhexidine Bathing}

Chlorhexidine $(\mathrm{CHG})$ is a widely used broad-spectrum topical antimicrobial agent [100]. The Centers for Disease Control and Prevention recommend its use as a skin cleanser prior to insertion of central venous catheters (CVC) in both children and adults but do not recommend its use in infants less than 2 months of age due to lack of safety and efficacy data in this population [101].

In spite of these cautions, a national survey of neonatology training program directors indicates that most NICUs use chlorhexidine for CVC site prep and maintenance but restrict use based on gestational age, chronological age, and birth weight [102]. Risks to premature infants relate to the increased potential for chemical burns and contact dermatitis in the setting of underdeveloped skin [100] and the possibility of systemic absorption of $\mathrm{CHG}$, although no adverse events have been reported despite demonstrable blood CHG levels [100, 103-105].

Chlorhexidine bathing has been suggested as another adjunct to decrease colonization and has been studied in adults and children, including neonates. An adult randomized controlled trial demonstrated that daily chlorhexidine bathing did not reduce HAI including central line-associated bloodstream infection (CLABSI), catheter-associated urinary tract infection (CAUTI), or ventilator-associated pneumonia (VAP) [106]. A number of other studies (including clinical trials) in adults, however, have shown positive benefits of chlorhexidine-containing products when used as part of a bundle approach for HAI prevention [107-109]. In the Pediatric SCRUB Trial, daily chlorhexidine bathing was compared with standard bathing practices to evaluate effect on incidence of bacteremia in critically ill children [110]. There was a non-statistically significant reduction in bacteremia in the CHG group in the intention-to-treat analysis and a $36 \%$ decrease in bacteremia in the per protocol arm [110].

The use of universal decolonization raises concerns about the possibility of chlorhexidine resistance. A study from Texas Children's Hospital found that nearly half of nosocomial $S$. aureus carried one or both genes associated with chlorhexidine tolerance ( $q a c A / q a c B$ and $s m r$ ), noting that $s m r$-positive isolates were more often resistant to methicillin, ciprofloxacin, or clindamycin as well [111]. Mupirocin resistance was also noted in $2.8 \%$ of the isolates in this study [111].

Vertical and horizontal approaches to infection prevention have been compared in two studies: Huang et al. compared three approaches to MRSA prevention among 74 adult ICU patients in the REDUCE-MRSA study [112]. Vertical approaches consisted of AST with and without targeted decolonization of MRSA carriers with CHG bathing and intranasal mupirocin compared with a horizontal approach involving universal decolonization of all ICU patients regardless of MRSA status. Universal decolonization was found to be associated with the largest reduction in all-cause BSI (44\%) and MRSA clinical culture rates (37\%) [112]. Another group showed that improved hand hygiene in addition to universal CHG bathing reduced overall infection rate and specific rates of Candida CAUTI and Acinetobacter VAP [113]. Additionally, when there is high adherence to CHG bathing and hand hygiene, 
there is no additional benefit to AST and isolation to reduce MDRO acquisition rates [114].

\section{Digestive and Respiratory Tract Decolonization/ Decontamination Strategies}

Selective digestive decontamination (SDD) and selective oral decontamination (SOD) are additional methods of universal decolonization employed in an effort to reduce colonization with gram-negative organisms, particularly in critically ill patients. Both methods use a polymyxin, an aminoglycoside, and an antifungal, applied to the oropharynx as a paste or gel (SOD) or in a liquid form administered per nasogastric or orogastric tube (SDD), paired with systemic antimicrobials, usually an intravenous third-generation cephalosporin. These two strategies have been studied in more than 50 RCTs and have been examined in 12 metaanalyses with demonstrated efficacy in reduction of colonization, morbidity, and mortality in adult ICU patients [115-117]. Widespread acceptance has been limited by concern over selecting for resistant organisms in universal applications, although long-term follow-up in units employing these strategies have not demonstrated an increase in resistant organisms [118]. Microbiome studies of adults undergoing SDD compared to healthy adults revealed dramatic shifts in the gastrointestinal microbiome of SDD recipients (as would be expected) as well as an increase in the relative abundance of organisms expressing antimicrobial resistance genes [119].

The pediatric experience with these strategies is limited. In a single meta-analysis of 4 RCTs including 335 children, ventilator-associated pneumonia rates were $69 \%$ lower in in those children receiving SDD [120]. The use in neonatal populations has not been studied.

\section{Surgical Site Infections}

The evidence for perioperative antimicrobial prophylaxis is well established, and the use of antimicrobials prior to incision reduces rates of SSI [121] by reducing the concentration of potential pathogens within or near the surgical incision. The basic tenets of antimicrobial use to prevent SSI include use of prophylaxis for all elective operations requiring entry into a hollow viscus, involving insertion of intravascular or orthopedic prosthetic devices or implants, or operations in which occurrence of SSI would pose catastrophic risk to the patient (e.g., sternotomy). The choice of antimicrobial is based upon a need for bactericidal activity against the expected pathogens for specific surgical procedures as well as agents which are known to be safe and cost-effective. The goal is to provide bactericidal concentrations in tissues and serum at the time of incision and to be continued throughout the entire operation until the wound is closed. Re-dosing of the antimicrobial agent may be required should the procedure last several hours or if there is significant blood loss. 
An important risk factor contributing to SSI risk is the number of organisms which gain entry into the wound intraoperatively. The greater the burden, the greater the risk of infection. When appropriate antimicrobial prophylaxis has been administered, a bacterial burden of $10^{5}$ is required to cause SSI; however if a foreign body is present, the threshold to cause infection may be significantly reduced. Virulence of the organism also contributes to SSI risk.

Pre- and perioperative antiseptics are utilized in order to decrease organism burden and thereby reduce the risk of SSI. Preoperative bathing with agents such as chlorhexidine has been shown to decrease the amount of endogenous flora on the skin but has not been shown to reduce rates of SSI in pooled analyses of adult surgical patients [122]. In certain very high-risk populations, however, such as cardiac and orthopedic surgery patients, preoperative chlorhexidine bathing has been associated with reduced rates of SSI (especially those due to S. aureus or MRSA) [123125]. It is likely that the benefits of chlorhexidine bathing are influenced by the type of surgical procedure (i.e., high-risk vs. low-risk) as well as the baseline rate of SSI at a given institution. In spite of these controversies, the use of chlorhexidine body wash prior to surgery is routine.

There are several options for preoperative skin antisepsis with either chlorhexidine-alcohol or povidone-iodine as the active agent. The authors of a Cochrane Review conclude that other characteristics of skin prep agents such as potential side effects and cost should be taken into consideration as well until there are definitive data showing clinical superiority of one agent over another [126]. New CDC Guidelines for Prevention of SSI recommend an alcohol-based skin antiseptic, such as either chlorhexidine-alcohol or iodophor-alcohol products [127-129].

Surgical site infections generally arise from endogenous sources such as bacteria present on skin surfaces or in a viscus, with greatest risk occurring while the wound is open. In addition to skin surface, bacteria may be found in skin appendages, including sebaceous glands, hair follicles, and sweat glands [130]. When infections related to exogenous sources occur, they may be sporadic or related to an outbreak. Exogenous sources include contamination of the operating room environment, surgical instruments, equipment, or colonized or infected personnel [131, 132].

\section{Environmental Contamination}

Common nosocomial pathogens can persist for months on surfaces, contributing to transmission risk in the absence of regular and thorough cleaning and disinfection [133]. These pathogens importantly include gram-positive (Enterococcus, including VRE; S. aureus, including MRSA; and Streptococcus pyogenes) as well as gramnegative (Acinetobacter spp., E. coli, Klebsiella spp., p. aeruginosa, Serratia marcescens, or Shigella) organisms. Spore-forming bacteria, such as Clostridium difficile, can survive for months as can fungi and yeast. Viruses from the respiratory tract, such as coronavirus, influenza, coxsackie, and rhinovirus, survive a relatively short period of days, whereas viruses from the gastrointestinal tract, such as norovirus or rotavirus, may persist for up to 2 months [133]. 
Surfaces in rooms of patients infected or colonized with pathogens may (and frequently do) become contaminated. MRSA, VRE, Acinetobacter spp., norovirus, and $C$. difficile have been detected on environmental surfaces in rooms of infected or colonized patients, can colonize healthcare workers' hands, and can then be transmitted to others [134]. Contact with the environment is as likely as contact with the affected patient to result in contamination of HCW hands [32]. The presence of environmental contamination is a risk factor for $\mathrm{HCW}$ hand/glove contamination [33]. Admission to a room previously occupied by a patient colonized or infected with MRSA, VRE, Acinetobacter spp., or $C$. difficile has been shown to be a risk factor for subsequent development of colonization or infection by these pathogens [38, 40, 41].

Multiple studies have demonstrated that a lack of thorough cleaning $[135,136]$ contributes to persistence of environmental contamination. Assessing adequacy of cleaning can be performed using various methods including observation for visible soiling, culture-based colony counts, fluorescent dye, and ATP detection. For example, fluorescent dye can be applied as a dot to surfaces where it dries clear. If a surface was inadequately wiped, the area fluoresces when exposed to black light. ATP bioluminescence systems measure ATP, a marker for presence of residual organic material (e.g., human secretions or excretions and food). ATP, however, does not indicate presence of viable pathogens, and its absence does not rule out the presence of contamination, and as such, use of fluorescent dye correlates more closely with colony counts than does ATP bioluminescence [137].

Focused efforts to eradicate pathogens can improve cleaning efficacy, which may involve specialized teams [138] or through use of improved monitoring of cleaning practices with markers such as ATP and fluorescent dye [137, 139]. Feedback to environmental services (EVS) staff following use of enhanced methods has also been demonstrated to improve the frequency of achieving adequate cleaning [140, 141]. In a study of 36 acute care hospitals, only $48 \%(9910 / 20,646)$ of environmental surfaces were cleaned at baseline. After educational and procedural interventions combined with provision of objective performance feedback to EVS staff, 77\% (7287/9464) of surfaces were cleaned $(p<0.001)$ [141].

In addition to ensuring each surface is cleaned, it is important to select the correct cleaning product as microorganisms vary in their resistance to disinfectants. For example, disinfection of a room potentially contaminated by $C$. difficile requires use of hypochlorite-based solutions [142] rather than phenols or quaternary ammonium compounds generally used for general hospital-based cleaning.

In spite of enhanced cleaning methods aimed at improving cleaning thoroughness and monitoring of cleaning practices, many surfaces remain inadequately cleaned. For this reason, no-touch room disinfection units that decontaminate environmental surfaces and objects utilizing either ultraviolet (UV) light or hydrogen peroxide (HP) vapor have been developed [143, 144]. These technologies are considered an adjunct to standard cleaning and disinfection since surfaces must be physically clean and the room must be emptied of people prior to use. UV irradiation with certain wavelengths breaks the molecular bond in DNA, thereby destroying the organism. This has been shown to be effective against MRSA, VRE, and Acinetobacter baumannii, in experimentally contaminated rooms [145]. Systems utilizing HP vapor have been 
found to be effective in eradicating pathogens such as MRSA, Mycobacterium tuberculosis, Serratia, and C. difficile spores from rooms and equipment [146]. Both of these methods have been found to be effective at reducing HAIs [146]. Their advantages include ability to substantially reduce $C$. difficile spores [147] as well as achieve substantial reductions in vegetative bacteria.

Failure to adequately clean and sterilize equipment may lead to transmission via contaminated equipment [148]. The level of disinfection or sterilization considered acceptable depends on the intended use of the object and is categorized as critical (items that come into contact with sterile tissue), semicritical (items contacting mucous membranes, such as endoscopes), and noncritical (items contacting skin, such as stethoscopes). These each require sterilization, high-level disinfection, or low-level disinfection, respectively. Cleaning should precede sterilization or disinfection.

\section{Legionella and Other Water-Associated Infections}

Among the many sources of infection within hospital environments, water remains of significant concern secondary to opportunity for exposure. Water is ubiquitous in its use throughout the hospital, not only for routine sanitation but also for air conditioning, mechanical ventilation, bathing, as well as the cleaning and processing of equipment. Certain organisms have special predilection for moist environments and include gram-negative bacilli, nontuberculous mycobacteria, fungi, and some viruses. In a recent review of waterborne healthcare-associated infections, 41 of 125 reports described hospitalized children [149]. The organisms primarily responsible included Legionella (hot water distribution systems), Pseudomonas (bottled water), and Burkholderia (distilled and sterile water contamination) [149]. Generally, tap water is the most frequently reported source of infection, with contamination at the sink, shower, and bathtub. Legionella was the primary cause of HAI among all the patients included in this review and was the predominant organism causing outbreaks [149]. Legionella outbreaks have been reported in premature neonates associated with the humidification trays of incubators [150] and in term neonates associated with cold mist humidifiers [151].

Environmental control measures are generally insufficient, and eradication requires use of a multistep control plan which includes education; use of sterile water for immunocompromised patients; use of periodic cleaning of showers, tubs, and sinks; and use of disinfection systems/filters on taps and shower heads. A team of specialists from all areas of infection control including engineers is required to eradicate contamination in the water system/supplies when it occurs [149].

\section{Conclusion}

Endogenous and exogenous microbes are a constant threat to hospitalized patients. Efforts to decrease endogenous pathogens via decolonization and skin antisepsis decrease the risk of infection in some settings. Controlling the spread of potential 
pathogens from the environment requires meticulous attention to cleaning and disinfection practices as well as hand hygiene.

\section{References}

1. Wertheim HF, Melles DC, Vos MC, van Leeuwen W, van Belkum A, Verbrugh HA, et al. The role of nasal carriage in Staphylococcus aureus infections. Lancet Infect Dis. 2005;5(12):751-62.

2. Bogaert D, Keijser B, Huse S, Rossen J, Veenhoven R, van Gils E, et al. Variability and diversity of nasopharyngeal microbiota in children: a metagenomic analysis. PLoS One. 2011;6(2):e17035.

3. Iwase T, Uehara Y, Shinji H, Tajima A, Seo H, Takada K, et al. Staphylococcus epidermidis Esp inhibits Staphylococcus aureus biofilm formation and nasal colonization. Nature. 2010;465(7296):346-9.

4. Grice EA, Segre JA. The skin microbiome. Nat Rev Microbiol. 2011;9(4):244-53.

5. Dessinioti C, Katsambas AD. The role of Propionibacterium acnes in acne pathogenesis: facts and controversies. Clin Dermatol. 2010;28(1):2-7.

6. Hanifin JM, Rogge JL. Staphylococcal infections in patients with atopic dermatitis. Arch Dermatol. 1977;113(10):1383-6.

7. Ferrer M, Mendez-Garcia C, Rojo D, Barbas C, Moya A. Antibiotic use and microbiome function. Biochem Pharmacol. 2017;134:114-26.

8. Young VB. The role of the microbiome in human health and disease: an introduction for clinicians. BMJ. 2017;356:j831.

9. Jacobs MC, Haak BW, Hugenholtz F, Wiersinga WJ. Gut microbiota and host defense in critical illness. Curr Opin Crit Care. 2017;23(4):257-63.

10. Singhi SC, Kumar S. Probiotics in critically ill children. F1000Res. 2016;5:F1000 Faculty Rev-407. https://doi.org/10.12688/f1000research.7630.1. eCollection 2016.

11. Huang XZ, Zhu LB, Li ZR, Lin J. Bacterial colonization and intestinal mucosal barrier development. World J Clin Pediatr. 2013;2(4):46-53.

12. Biedermann L, Rogler G. The intestinal microbiota: its role in health and disease. Eur $\mathbf{J}$ Pediatr. 2015;174(2):151-67.

13. Woof JM, Kerr MA. The function of immunoglobulin A in immunity. J Pathol. 2006;208(2):270-82.

14. Gutzeit C, Magri G, Cerutti A. Intestinal $\operatorname{IgA}$ production and its role in host-microbe interaction. Immunol Rev. 2014;260(1):76-85.

15. Huang YC, Chou YH, Su LH, Lien RI, Lin TY. Methicillin-resistant Staphylococcus aureus colonization and its association with infection among infants hospitalized in neonatal intensive care units. Pediatrics. 2006;118(2):469-74.

16. von Eiff C, Becker K, Machka K, Stammer H, Peters G. Nasal carriage as a source of Staphylococcus aureus bacteremia. Study Group. N Engl J Med. 2001;344(1):11-6.

17. Perl TM, Cullen JJ, Wenzel RP, Zimmerman MB, Pfaller MA, Sheppard D, et al. Intranasal mupirocin to prevent postoperative Staphylococcus aureus infections. N Engl J Med. 2002;346(24):1871-7.

18. Johnston CP, Cooper L, Ruby W, Carroll KC, Cosgrove SE, Perl TM. Epidemiology of community-acquired methicillin-resistant Staphylococcus aureus skin infections among healthcare workers in an outpatient clinic. Infect Control Hosp Epidemiol. 2006;27(10):1133-6.

19. Atta MG, Eustace JA, Song X, Perl TM, Scheel PJ Jr. Outpatient vancomycin use and vancomycin-resistant enterococcal colonization in maintenance dialysis patients. Kidney Int. 2001;59(2):718-24.

20. Otter JA. What's trending in the infection prevention and control literature? From HIS 2012 to HIS 2014, and beyond. J Hosp Infect. 2015;89(4):229-36. 
21. Lin MY, Lyles-Banks RD, Lolans K, Hines DW, Spear JB, Petrak R, et al. The importance of long-term acute care hospitals in the regional epidemiology of Klebsiella pneumoniae carbapenemase-producing Enterobacteriaceae. Clin Infect Dis. 2013;57(9):1246-52.

22. Dancer SJ. Controlling hospital-acquired infection: focus on the role of the environment and new technologies for decontamination. Clin Microbiol Rev. 2014;27(4):665-90.

23. Nseir S, Blazejewski C, Lubret R, Wallet F, Courcol R, Durocher A. Risk of acquiring multidrug-resistant gram-negative bacilli from prior room occupants in the intensive care unit. Clin Microbiol Infect. 2011;17(8):1201-8.

24. Wendt C, Dietze B, Dietz E, Ruden H. Survival of Acinetobacter baumannii on dry surfaces. J Clin Microbiol. 1997;35(6):1394-7.

25. Drees M, Snydman DR, Schmid CH, Barefoot L, Hansjosten K, Vue PM, et al. Antibiotic exposure and room contamination among patients colonized with vancomycin-resistant enterococci. Infect Control Hosp Epidemiol. 2008;29(8):709-15.

26. Bonten MJ, Hayden MK, Nathan C, van Voorhis J, Matushek M, Slaughter S, et al. Epidemiology of colonisation of patients and environment with vancomycin-resistant enterococci. Lancet. 1996;348(9042):1615-9.

27. Kim KH, Fekety R, Batts DH, Brown D, Cudmore M, Silva J Jr, et al. Isolation of Clostridium difficile from the environment and contacts of patients with antibiotic-associated colitis. J Infect Dis. 1981;143(1):42-50.

28. McFarland LV, Mulligan ME, Kwok RY, Stamm WE. Nosocomial acquisition of Clostridium difficile infection. N Engl J Med. 1989;320(4):204-10.

29. Riggs MM, Sethi AK, Zabarsky TF, Eckstein EC, Jump RL, Donskey CJ. Asymptomatic carriers are a potential source for transmission of epidemic and nonepidemic Clostridium difficile strains among long-term care facility residents. Clin Infect Dis. 2007;45(8): 992-8.

30. Dumford DM 3rd, Nerandzic MM, Eckstein BC, Donskey CJ. What is on that keyboard? Detecting hidden environmental reservoirs of Clostridium difficile during an outbreak associated with North American pulsed-field gel electrophoresis type 1 strains. Am J Infect Control. 2009;37(1):15-9.

31. Huslage K, Rutala WA, Sickbert-Bennett E, Weber DJ. A quantitative approach to defining "high-touch" surfaces in hospitals. Infect Control Hosp Epidemiol. 2010;31(8):850-3.

32. Stiefel U, Cadnum JL, Eckstein BC, Guerrero DM, Tima MA, Donskey CJ. Contamination of hands with methicillin-resistant Staphylococcus aureus after contact with environmental surfaces and after contact with the skin of colonized patients. Infect Control Hosp Epidemiol. 2011;32(2):185-7.

33. Morgan DJ, Rogawski E, Thom KA, Johnson JK, Perencevich EN, Shardell M, et al. Transfer of multidrug-resistant bacteria to healthcare workers' gloves and gowns after patient contact increases with environmental contamination. Crit Care Med. 2012;40(4):1045-51.

34. Samore MH, Venkataraman L, DeGirolami PC, Arbeit RD, Karchmer AW. Clinical and molecular epidemiology of sporadic and clustered cases of nosocomial Clostridium difficile diarrhea. Am J Med. 1996;100(1):32-40.

35. Cohen B, Cohen CC, Loyland B, Larson EL. Transmission of health care-associated infections from roommates and prior room occupants: a systematic review. Clin Epidemiol. 2017;9:297-310.

36. Lemmen SW, Hafner H, Zolldann D, Stanzel S, Lutticken R. Distribution of multi-resistant gram-negative versus gram-positive bacteria in the hospital inanimate environment. J Hosp Infect. 2004;56(3):191-7.

37. Boyce JM, Potter-Bynoe G, Chenevert C, King T. Environmental contamination due to methicillin-resistant Staphylococcus aureus: possible infection control implications. Infect Control Hosp Epidemiol. 1997;18(9):622-7.

38. Huang SS, Datta R, Platt R. Risk of acquiring antibiotic-resistant bacteria from prior room occupants. Arch Intern Med. 2006;166(18):1945-51.

39. Rutala WA, Weber DJ. Disinfection and sterilization in health care facilities: an overview and current issues. Infect Dis Clin N Am. 2016;30(3):609-37. 
40. Carling P. Methods for assessing the adequacy of practice and improving room disinfection. Am J Infect Control. 2013;41(5 Suppl):S20-5.

41. Shaughnessy MK, Micielli RL, DePestel DD, Arndt J, Strachan CL, Welch KB, et al. Evaluation of hospital room assignment and acquisition of Clostridium difficile infection. Infect Control Hosp Epidemiol. 2011;32(3):201-6.

42. Donskey CJ. Does improving surface cleaning and disinfection reduce health care-associated infections? Am J Infect Control. 2013;41(5 Suppl):S12-9.

43. Boyce JM, Havill NL, Otter JA, McDonald LC, Adams NM, Cooper T, et al. Impact of hydrogen peroxide vapor room decontamination on Clostridium difficile environmental contamination and transmission in a healthcare setting. Infect Control Hosp Epidemiol. 2008;29(8):723-9.

44. Passaretti CL, Otter JA, Reich NG, Myers J, Shepard J, Ross T, et al. An evaluation of environmental decontamination with hydrogen peroxide vapor for reducing the risk of patient acquisition of multidrug-resistant organisms. Clin Infect Dis. 2013;56(1):27-35.

45. Septimus E, Weinstein RA, Perl TM, Goldmann DA, Yokoe DS. Approaches for preventing healthcare-associated infections: go long or go wide? Infect Control Hosp Epidemiol. 2014;35(Suppl 2):S10-4.

46. Septimus EJ, Schweizer ML. Decolonization in prevention of health care-associated infections. Clin Microbiol Rev. 2016;29(2):201-22.

47. Wenzel RP, Edmond MB. Infection control: the case for horizontal rather than vertical interventional programs. Int J Infect Dis. 2010;14(Suppl 4):S3-5.

48. Wenzel RP, Bearman G, Edmond MB. Screening for MRSA: a flawed hospital infection control intervention. Infect Control Hosp Epidemiol. 2008;29(11):1012-8.

49. Williams RE. Healthy carriage of Staphylococcus aureus: its prevalence and importance. Bacteriol Rev. 1963;27:56-71.

50. Armstrong-Esther CA. Carriage patterns of Staphylococcus aureus in a healthy non-hospital population of adults and children. Ann Hum Biol. 1976;3(3):221-7.

51. Wertheim HF, Verveer J, Boelens HA, van Belkum A, Verbrugh HA, Vos MC. Effect of mupirocin treatment on nasal, pharyngeal, and perineal carriage of Staphylococcus aureus in healthy adults. Antimicrob Agents Chemother. 2005;49(4):1465-7.

52. Ridley M. Perineal carriage of Staph. aureus. Br Med J. 1959;1(5117):270-3.

53. Guinan ME, Dan BB, Guidotti RJ, Reingold AL, Schmid GP, Bettoli EJ, et al. Vaginal colonization with Staphylococcus aureus in healthy women: a review of four studies. Ann Intern Med. 1982;96(6 Pt 2):944-7.

54. Faron ML, Ledeboer NA, Buchan BW. Resistance mechanisms, epidemiology, and approaches to screening for vancomycin-resistant Enterococcus in the health care setting. J Clin Microbiol. 2016;54(10):2436-47.

55. Cooper BS, Stone SP, Kibbler CC, Cookson BD, Roberts JA, Medley GF, et al. Isolation measures in the hospital management of methicillin resistant Staphylococcus aureus (MRSA): systematic review of the literature. BMJ. 2004;329(7465):533.

56. Glick SB, Samson DJ, Huang ES, Vats V, Aronson N, Weber SG. Screening for methicillinresistant Staphylococcus aureus: a comparative effectiveness review. Am J Infect Control. 2014;42(2):148-55.

57. Christiansen KJ, Tibbett PA, Beresford W, Pearman JW, Lee RC, Coombs GW, et al. Eradication of a large outbreak of a single strain of vanB vancomycin-resistant Enterococcus faecium at a major Australian teaching hospital. Infect Control Hosp Epidemiol. 2004;25(5):384-90.

58. Jernigan JA, Titus MG, Groschel DH, Getchell-White S, Farr BM. Effectiveness of contact isolation during a hospital outbreak of methicillin-resistant Staphylococcus aureus. Am J Epidemiol. 1996;143(5):496-504.

59. Harris AD, Pineles L, Belton B, Johnson JK, Shardell M, Loeb M, et al. Universal glove and gown use and acquisition of antibiotic-resistant bacteria in the ICU: a randomized trial. JAMA. 2013;310(15):1571-80.

60. Cepeda JA, Whitehouse T, Cooper B, Hails J, Jones K, Kwaku F, et al. Isolation of patients in single rooms or cohorts to reduce spread of MRSA in intensive-care units: prospective twocentre study. Lancet. 2005;365(9456):295-304. 
61. Morgan DJ, Kaye KS, Diekema DJ. Reconsidering isolation precautions for endemic methicillin-resistant Staphylococcus aureus and vancomycin-resistant Enterococcus. JAMA. 2014;312(14):1395-6.

62. Bracco D, Dubois MJ, Bouali R, Eggimann P. Single rooms may help to prevent nosocomial bloodstream infection and cross-transmission of methicillin-resistant Staphylococcus aureus in intensive care units. Intensive Care Med. 2007;33(5):836-40.

63. Gastmeier P, Schwab F, Geffers C, Ruden H. To isolate or not to isolate? Analysis of data from the German Nosocomial Infection Surveillance System regarding the placement of patients with methicillin-resistant Staphylococcus aureus in private rooms in intensive care units. Infect Control Hosp Epidemiol. 2004;25(2):109-13.

64. Coia JE, Duckworth GJ, Edwards DI, Farrington M, Fry C, Humphreys H, et al. Guidelines for the control and prevention of meticillin-resistant Staphylococcus aureus (MRSA) in healthcare facilities. J Hosp Infect. 2006;63(Suppl 1):S1-44.

65. Calfee DP, Salgado CD, Milstone AM, Harris AD, Kuhar DT, Moody J, et al. Strategies to prevent methicillin-resistant Staphylococcus aureus transmission and infection in acute care hospitals: 2014 update. Infect Control Hosp Epidemiol. 2014;35(7):772-96.

66. Fatkenheuer G, Hirschel B, Harbarth S. Screening and isolation to control meticillin-resistant Staphylococcus aureus: sense, nonsense, and evidence. Lancet. 2015;385(9973):1146-9.

67. Russell DL, Flood A, Zaroda TE, Acosta C, Riley MM, Busuttil RW, et al. Outcomes of colonization with MRSA and VRE among liver transplant candidates and recipients. Am J Transplant. 2008;8(8):1737-43.

68. Kluytmans J, van Belkum A, Verbrugh H. Nasal carriage of Staphylococcus aureus: epidemiology, underlying mechanisms, and associated risks. Clin Microbiol Rev. 1997;10(3):505-20.

69. VandenBergh MF, Yzerman EP, van Belkum A, Boelens HA, Sijmons M, Verbrugh HA. Follow-up of Staphylococcus aureus nasal carriage after 8 years: redefining the persistent carrier state. J Clin Microbiol. 1999;37(10):3133-40.

70. Nouwen JL, Fieren MW, Snijders S, Verbrugh HA, van Belkum A. Persistent (not intermittent) nasal carriage of Staphylococcus aureus is the determinant of CPD-related infections. Kidney Int. 2005;67(3):1084-92.

71. Kalmeijer MD, van Nieuwland-Bollen E, Bogaers-Hofman D, de Baere GA. Nasal carriage of Staphylococcus aureus is a major risk factor for surgical-site infections in orthopedic surgery. Infect Control Hosp Epidemiol. 2000;21(5):319-23.

72. Mermel LA, Eells SJ, Acharya MK, Cartony JM, Dacus D, Fadem S, et al. Quantitative analysis and molecular fingerprinting of methicillin-resistant Staphylococcus aureus nasal colonization in different patient populations: a prospective, multicenter study. Infect Control Hosp Epidemiol. 2010;31(6):592-7.

73. Cheng VC, Li IW, Wu AK, Tang BS, Ng KH, To KK, et al. Effect of antibiotics on the bacterial load of meticillin-resistant Staphylococcus aureus colonisation in anterior nares. J Hosp Infect. 2008;70(1):27-34.

74. Milstone AM, Budd A, Shepard JW, Ross T, Aucott S, Carroll KC, et al. Role of decolonization in a comprehensive strategy to reduce methicillin-resistant Staphylococcus aureus infections in the neonatal intensive care unit: an observational cohort study. Infect Control Hosp Epidemiol. 2010;31(5):558-60.

75. Khoury J, Jones M, Grim A, Dunne WM Jr, Fraser V. Eradication of methicillin-resistant Staphylococcus aureus from a neonatal intensive care unit by active surveillance and aggressive infection control measures. Infect Control Hosp Epidemiol. 2005;26(7): 616-21.

76. Huang YC, Lien RI, Su LH, Chou YH, Lin TY. Successful control of methicillin-resistant Staphylococcus aureus in endemic neonatal intensive care units - a 7-year campaign. PLoS One. 2011;6(8):e23001.

77. Harbarth S, Dharan S, Liassine N, Herrault P, Auckenthaler R, Pittet D. Randomized, placebo-controlled, double-blind trial to evaluate the efficacy of mupirocin for eradicating carriage of methicillin-resistant Staphylococcus aureus. Antimicrob Agents Chemother. 1999;43(6):1412-6. 
78. Ammerlaan HS, Kluytmans JA, Wertheim HF, Nouwen JL, Bonten MJ. Eradication of methicillin-resistant Staphylococcus aureus carriage: a systematic review. Clin Infect Dis. 2009;48(7):922-30.

79. Tacconelli E, Carmeli Y, Aizer A, Ferreira G, Foreman MG, D'Agata EM. Mupirocin prophylaxis to prevent Staphylococcus aureus infection in patients undergoing dialysis: a metaanalysis. Clin Infect Dis. 2003;37(12):1629-38.

80. van Rijen MM, Bonten M, Wenzel RP, Kluytmans JA. Intranasal mupirocin for reduction of Staphylococcus aureus infections in surgical patients with nasal carriage: a systematic review. J Antimicrob Chemother. 2008;61(2):254-61.

81. Kallen AJ, Wilson CT, Larson RJ. Perioperative intranasal mupirocin for the prevention of surgical-site infections: systematic review of the literature and meta-analysis. Infect Control Hosp Epidemiol. 2005;26(12):916-22.

82. van Rijen M, Bonten M, Wenzel R, Kluytmans J. Mupirocin ointment for preventing Staphylococcus aureus infections in nasal carriers. Cochrane Database Syst Rev. 2008;4:CD006216.

83. Robicsek A, Beaumont JL, Paule SM, Hacek DM, Thomson RB Jr, Kaul KL, et al. Universal surveillance for methicillin-resistant Staphylococcus aureus in 3 affiliated hospitals. Ann Intern Med. 2008;148(6):409-18.

84. Jain R, Kralovic SM, Evans ME, Ambrose M, Simbartl LA, Obrosky DS, et al. Veterans Affairs initiative to prevent methicillin-resistant Staphylococcus aureus infections. N Engl J Med. 2011;364(15):1419-30.

85. Harbarth S, Fankhauser C, Schrenzel J, Christenson J, Gervaz P, Bandiera-Clerc C, et al. Universal screening for methicillin-resistant Staphylococcus aureus at hospital admission and nosocomial infection in surgical patients. JAMA. 2008;299(10):1149-57.

86. Huang YC, Lien RI, Lin TY. Effect of mupirocin decolonization on subsequent methicillinresistant Staphylococcus aureus infection in infants in neonatal intensive care units. Pediatr Infect Dis J. 2015;34(3):241-5.

87. Popoola VO, Budd A, Wittig SM, Ross T, Aucott SW, Perl TM, et al. Methicillin-resistant Staphylococcus aureus transmission and infections in a neonatal intensive care unit despite active surveillance cultures and decolonization: challenges for infection prevention. Infect Control Hosp Epidemiol. 2014;35(4):412-8.

88. Calfee DP, Salgado CD, Milstone AM, Harris AD, Kuhar DT, Moody J, et al. Strategies to prevent methicillin-resistant Staphylococcus aureus transmission and infection in acute care hospitals: 2014 update. Infect Control Hosp Epidemiol. 2014;35(Suppl 2):S108-32.

89. Milstone AM, Song X, Coffin S, Elward A, Society for Healthcare Epidemiology of America's Pediatric Special Interest G. Identification and eradication of methicillin-resistant Staphylococcus aureus colonization in the neonatal intensive care unit: results of a national survey. Infect Control Hosp Epidemiol. 2010;31(7):766-8.

90. Ericson JE, Popoola VO, Smith PB, Benjamin DK, Fowler VG, Benjamin DK Jr, et al. Burden of invasive Staphylococcus aureus infections in hospitalized infants. JAMA Pediatr. 2015;169(12):1105-11.

91. Popoola VO, Colantuoni E, Suwantarat N, Pierce R, Carroll KC, Aucott SW, et al. Active surveillance cultures and decolonization to reduce Staphylococcus aureus infections in the neonatal intensive care unit. Infect Control Hosp Epidemiol. 2016;37(4):381-7.

92. Delaney HM, Wang E, Melish M. Comprehensive strategy including prophylactic mupirocin to reduce Staphylococcus aureus colonization and infection in high-risk neonates. J Perinatol. 2013;33(4):313-8.

93. Hitomi S, Kubota M, Mori N, Baba S, Yano H, Okuzumi K, et al. Control of a methicillinresistant Staphylococcus aureus outbreak in a neonatal intensive care unit by unselective use of nasal mupirocin ointment. J Hosp Infect. 2000;46(2):123-9.

94. Lee BY, Wiringa AE, Bailey RR, Goyal V, Lewis GJ, Tsui BY, et al. Screening cardiac surgery patients for MRSA: an economic computer model. Am J Manag Care. 2010;16(7):e163-73.

95. Holton DL, Nicolle LE, Diley D, Bernstein K. Efficacy of mupirocin nasal ointment in eradicating Staphylococcus aureus nasal carriage in chronic haemodialysis patients. J Hosp Infect. 1991;17(2):133-7. 
96. Immerman I, Ramos NL, Katz GM, Hutzler LH, Phillips MS, Bosco JA 3rd. The persistence of Staphylococcus aureus decolonization after mupirocin and topical chlorhexidine: implications for patients requiring multiple or delayed procedures. J Arthroplast. 2012;27(6):870-6.

97. Schweizer M, Perencevich E, McDanel J, Carson J, Formanek M, Hafner J, et al. Effectiveness of a bundled intervention of decolonization and prophylaxis to decrease gram positive surgical site infections after cardiac or orthopedic surgery: systematic review and meta-analysis. BMJ. 2013;346:f2743.

98. Silvetti S, Ranucci M, Isgro G, Villa V, Costa E. Preoperative colonization in pediatric cardiac surgery and its impact on postoperative infections. Paediatr Anaesth. 2017;27(8):849-55.

99. Bode LG, Kluytmans JA, Wertheim HF, Bogaers D, Vandenbroucke-Grauls CM, Roosendaal $\mathrm{R}$, et al. Preventing surgical-site infections in nasal carriers of Staphylococcus aureus. N Engl J Med. 2010;362(1):9-17.

100. Chapman AK, Aucott SW, Milstone AM. Safety of chlorhexidine gluconate used for skin antisepsis in the preterm infant. J Perinatol. 2012;32(1):4-9.

101. O'Grady NP, Alexander M, Burns LA, Dellinger EP, Garland J, Heard SO, et al. Summary of recommendations: guidelines for the prevention of intravascular catheter-related infections. Clin Infect Dis. 2011;52(9):1087-99.

102. Tamma PD, Aucott SW, Milstone AM. Chlorhexidine use in the neonatal intensive care unit: results from a national survey. Infect Control Hosp Epidemiol. 2010;31(8):846-9.

103. Aggett PJ, Cooper LV, Ellis SH, McAinsh J. Percutaneous absorption of chlorhexidine in neonatal cord care. Arch Dis Child. 1981;56(11):878-80.

104. Cowen J, Ellis SH, McAinsh J. Absorption of chlorhexidine from the intact skin of newborn infants. Arch Dis Child. 1979;54(5):379-83.

105. Garland JS, Alex CP, Uhing MR, Peterside IE, Rentz A, Harris MC. Pilot trial to compare tolerance of chlorhexidine gluconate to povidone-iodine antisepsis for central venous catheter placement in neonates. J Perinatol. 2009;29(12):808-13.

106. Noto MJ, Domenico HJ, Byrne DW, Talbot T, Rice TW, Bernard GR, et al. Chlorhexidine bathing and healthcare-associated infections: a randomized clinical trial. JAMA. 2015;313(4):369-78.

107. Frost SA, Alogso MC, Metcalfe L, Lynch JM, Hunt L, Sanghavi R, et al. Chlorhexidine bathing and health care-associated infections among adult intensive care patients: a systematic review and meta-analysis. Crit Care. 2016;20(1):379.

108. Bleasdale SC, Trick WE, Gonzalez IM, Lyles RD, Hayden MK, Weinstein RA. Effectiveness of chlorhexidine bathing to reduce catheter-associated bloodstream infections in medical intensive care unit patients. Arch Intern Med. 2007;167(19):2073-9.

109. Climo MW, Yokoe DS, Warren DK, Perl TM, Bolon M, Herwaldt LA, et al. Effect of daily chlorhexidine bathing on hospital-acquired infection. N Engl J Med. 2013;368(6):533-42.

110. Milstone AM, Elward A, Song X, Zerr DM, Orscheln R, Speck K, et al. Daily chlorhexidine bathing to reduce bacteraemia in critically ill children: a multicentre, cluster-randomised, crossover trial. Lancet. 2013;381(9872):1099-106.

111. McNeil JC, Kok EY, Vallejo JG, Campbell JR, Hulten KG, Mason EO, et al. Clinical and molecular features of decreased chlorhexidine susceptibility among nosocomial Staphylococcus aureus isolates at Texas Children's Hospital. Antimicrob Agents Chemother. 2016;60(2):1121-8.

112. Huang SS, Septimus E, Kleinman K, Moody J, Hickok J, Avery TR, et al. Targeted versus universal decolonization to prevent ICU infection. N Engl J Med. 2013;368(24):2255-65.

113. Martinez-Resendez MF, Garza-Gonzalez E, Mendoza-Olazaran S, Herrera-Guerra A, Rodriguez-Lopez JM, Perez-Rodriguez E, et al. Impact of daily chlorhexidine baths and hand hygiene compliance on nosocomial infection rates in critically ill patients. Am J Infect Control. 2014;42(7):713-7.

114. Derde LPG, Cooper BS, Goossens H, Malhotra-Kumar S, Willems RJL, Gniadkowski M, et al. Interventions to reduce colonisation and transmission of antimicrobial-resistant bacteria in intensive care units: an interrupted time series study and cluster randomised trial. Lancet Infect Dis. 2014;14(1):31-9. 
115. Price R, MacLennan G, Glen J. Selective digestive or oropharyngeal decontamination and topical oropharyngeal chlorhexidine for prevention of death in general intensive care: systematic review and network meta-analysis. BMJ. 2014;348:g2197.

116. Zhao D, Song J, Gao X, Gao F, Wu Y, Lu Y, et al. Selective oropharyngeal decontamination versus selective digestive decontamination in critically ill patients: a meta-analysis of randomized controlled trials. Drug Des Devel Ther. 2015;9:3617-24.

117. Plantinga NL, de Smet A, Oostdijk EAN, de Jonge E, Camus C, Krueger WA, et al. Selective digestive and oropharyngeal decontamination in medical and surgical ICU patients: individual patient data meta-analysis. Clin Microbiol Infect. 2017;24(5):505-13.

118. Houben AJ, Oostdijk EA, van der Voort PH, Monen JC, Bonten MJ, van der Bij AK. Selective decontamination of the oropharynx and the digestive tract, and antimicrobial resistance: a 4 year ecological study in 38 intensive care units in the Netherlands. J Antimicrob Chemother. 2014;69(3):797-804.

119. Buelow E, Bello Gonzalez TDJ, Fuentes S, de Steenhuijsen Piters WAA, Lahti L, Bayjanov $\mathrm{JR}$, et al. Comparative gut microbiota and resistome profiling of intensive care patients receiving selective digestive tract decontamination and healthy subjects. Microbiome. 2017;5(1):88.

120. Petros A, Silvestri L, Booth R, Taylor N, van Saene H. Selective decontamination of the digestive tract in critically ill children: systematic review and meta-analysis. Pediatr Crit Care Med. 2013;14(1):89-97.

121. Classen DC, Evans RS, Pestotnik SL, Horn SD, Menlove RL, Burke JP. The timing of prophylactic administration of antibiotics and the risk of surgical-wound infection. N Engl J Med. 1992;326(5):281-6.

122. Franco LM, Cota GF, Pinto TS, Ercole FF. Preoperative bathing of the surgical site with chlorhexidine for infection prevention: systematic review with meta-analysis. Am J Infect Control. 2017;45(4):343-9.

123. Kapadia BH, Elmallah RK, Mont MA. A randomized, clinical trial of preadmission chlorhexidine skin preparation for lower extremity total joint arthroplasty. J Arthroplasty. 2016;31(12):2856-61.

124. Saraswat MK, Magruder JT, Crawford TC, Gardner JM, Duquaine D, Sussman MS, et al. Preoperative Staphylococcus Aureus screening and targeted decolonization in cardiac surgery. Ann Thorac Surg. 2017;104(4):1349-56.

125. Wang Z, Zheng J, Zhao Y, Xiang Y, Chen X, Zhao F, et al. Preoperative bathing with chlorhexidine reduces the incidence of surgical site infections after total knee arthroplasty: a meta-analysis. Medicine (Baltimore). 2017;96(47):e8321.

126. Dumville JC, McFarlane E, Edwards P, Lipp A, Holmes A, Liu Z. Preoperative skin antiseptics for preventing surgical wound infections after clean surgery. Cochrane Database Syst Rev. 2015;4:CD003949.

127. Berrios-Torres SI, Umscheid CA, Bratzler DW, Leas B, Stone EC, Kelz RR, et al. Centers for Disease Control and Prevention guideline for the prevention of surgical site infection, 2017. JAMA Surg. 2017;152(8):784-91.

128. Darouiche RO, Wall MJ Jr, Itani KM, Otterson MF, Webb AL, Carrick MM, et al. Chlorhexidine-alcohol versus povidone-iodine for surgical-site antisepsis. N Engl J Med. 2010;362(1):18-26.

129. Thom KA, Escobar D, Boutin MA, Zhan M, Harris AD, Johnson JK. Frequent contamination of nursing scrubs is associated with specific care activities. Am J Infect Control. 2018;46(5):503-6.

130. Tuazon CU. Skin and skin structure infections in the patient at risk: carrier state of Staphylococcus aureus. Am J Med. 1984;76(5A):166-71.

131. Crusz SA, Yates C, Holden S, Kearns A, Boswell T. Prolonged outbreak of Staphylococcus aureus surgical site infection traced to a healthcare worker with psoriasis. J Hosp Infect. 2014;86(1):42-6.

132. van Ingen J, Kohl TA, Kranzer K, Hasse B, Keller PM, Katarzyna Szafranska A, et al. Global outbreak of severe Mycobacterium chimaera disease after cardiac surgery: a molecular epidemiological study. Lancet Infect Dis. 2017;17(10):1033-41. 
133. Kramer A, Schwebke I, Kampf G. How long do nosocomial pathogens persist on inanimate surfaces? A systematic review. BMC Infect Dis. 2006;6:130.

134. Otter JA, Yezli S, French GL. The role played by contaminated surfaces in the transmission of nosocomial pathogens. Infect Control Hosp Epidemiol. 2011;32(7):687-99.

135. Carling PC, Parry MF, Von Beheren SM, Healthcare Environmental Hygiene Study G. Identifying opportunities to enhance environmental cleaning in 23 acute care hospitals. Infect Control Hosp Epidemiol. 2008;29(1):1-7.

136. Carling PC, Von Beheren S, Kim P, Woods C, Healthcare Environmental Hygiene Study G. Intensive care unit environmental cleaning: an evaluation in sixteen hospitals using a novel assessment tool. J Hosp Infect. 2008;68(1):39-44.

137. Boyce JM, Havill NL, Havill HL, Mangione E, Dumigan DG, Moore BA. Comparison of fluorescent marker systems with 2 quantitative methods of assessing terminal cleaning practices. Infect Control Hosp Epidemiol. 2011;32(12):1187-93.

138. Eckstein BC, Adams DA, Eckstein EC, Rao A, Sethi AK, Yadavalli GK, et al. Reduction of Clostridium difficile and vancomycin-resistant Enterococcus contamination of environmental surfaces after an intervention to improve cleaning methods. BMC Infect Dis. 2007;7:61.

139. Boyce JM, Havill NL, Dumigan DG, Golebiewski M, Balogun O, Rizvani R. Monitoring the effectiveness of hospital cleaning practices by use of an adenosine triphosphate bioluminescence assay. Infect Control Hosp Epidemiol. 2009;30(7):678-84.

140. Goodman ER, Platt R, Bass R, Onderdonk AB, Yokoe DS, Huang SS. Impact of an environmental cleaning intervention on the presence of methicillin-resistant Staphylococcus aureus and vancomycin-resistant enterococci on surfaces in intensive care unit rooms. Infect Control Hosp Epidemiol. 2008;29(7):593-9.

141. Carling PC, Parry MM, Rupp ME, Po JL, Dick B, Von Beheren S, et al. Improving cleaning of the environment surrounding patients in 36 acute care hospitals. Infect Control Hosp Epidemiol. 2008;29(11):1035-41.

142. McDonnell G, Russell AD. Antiseptics and disinfectants: activity, action, and resistance. Clin Microbiol Rev. 1999;12(1):147-79.

143. Rutala WA, Weber DJ. Are room decontamination units needed to prevent transmission of environmental pathogens? Infect Control Hosp Epidemiol. 2011;32(8):743-7.

144. Davies A, Pottage T, Bennett A, Walker J. Gaseous and air decontamination technologies for Clostridium difficile in the healthcare environment. J Hosp Infect. 2011;77(3):199-203.

145. Rutala WA, Gergen MF, Weber DJ. Room decontamination with UV radiation. Infect Control Hosp Epidemiol. 2010;31(10):1025-9.

146. Weber DJ, Rutala WA, Anderson DJ, Chen LF, Sickbert-Bennett EE, Boyce JM. Effectiveness of ultraviolet devices and hydrogen peroxide systems for terminal room decontamination: focus on clinical trials. Am J Infect Control. 2016;44(5 Suppl):e77-84.

147. Rutala WA, Weber DJ. Selection of the ideal disinfectant. Infect Control Hosp Epidemiol. 2014;35(7):855-65.

148. 2018. Available from: https://www.cdc.gov/infectioncontrol/pdf/guidelines/disinfectionguidelines.pdf.

149. Ferranti G, Marchesi I, Favale M, Borella P, Bargellini A. Aetiology, source and prevention of waterborne healthcare-associated infections: a review. J Med Microbiol. 2014;63(Pt 10): $1247-59$.

150. Verissimo A, Vesey G, Rocha GM, Marrao G, Colbourne J, Dennis PJ, et al. A hot water supply as the source of Legionella pneumophila in incubators of a neonatology unit. J Hosp Infect. 1990;15(3):255-63.

151. Yiallouros PK, Papadouri T, Karaoli C, Papamichael E, Zeniou M, Pieridou-Bagatzouni D, et al. First outbreak of nosocomial Legionella infection in term neonates caused by a cold mist ultrasonic humidifier. Clin Infect Dis. 2013;57(1):48-56. 